\title{
Implementation Requirements for Patient Discharge Planning in Health System: A qualitative study in Iran
}

\author{
Masumeh Gholizadeh ${ }^{1}$, Ali Janati ${ }^{1} *$, Bahram Delgoshaei ${ }^{2}$, Hasan Abulghasem \\ Gorji $^{2}$, Sogand Tourani ${ }^{2}$
}

\section{OPEN ACCESS}

Citation: Masumeh Gholizadeh, Ali Janati, Bahram Delgoshaei, Hasan Abulghasem Gorji, Sogand Tourani. Implementation Requirements for Patient Discharge Planning in Health System: A qualitative study in Iran. Ethiop J Sci.2018;28(2):157. doi:http://dx.doi.org/10.4314/ejhs.v28i2.7

Received: September 7, 2017

Accepted: September 8, 2017

Published: March 1, 2018

Copyright: (C) 2018 Masumeh G., et al

This is an open access article distributed under the terms of the Creative Commons Attribution License, which permits unrestricted use, distribution, and reproduction in any medium, provided the original author and source are credited.

Funding: Nil

Competing Interests: The authors declare that this manuscript was approved by all authors in its form and that no competing interest exists.

Affiliation and Correspondence:

${ }^{1}$ Departement of Health Services

Management, Iranian Center of

Excellence in Health Management,

School of Management and Medical

Informatics, Tabriz University of

Medical Sciences, Tabriz, Iran

${ }^{2}$ Department of Health Services

Management, School of Health

Management and Information

Sciences, Iran University of Medical

Sciences, Tehran, Iran

*Email: Janati1382@gmail.com
ABSTRACT

BACKGROUND: Effective discharge planning plays a vital role in care continuity and integrated care. Identifying and providing infrastructures for discharge planning can reduce avoidable hospital readmissions and finally lead to improvement of quality of care. The current study aimed to identify the requirements of discharge planning from the perspective of professionals in the health system of Iran.

METHODS: For the purposes of this qualitative study, semistructured interviews and sessions of focus group discussions with experts in the field were conducted. The data were analyzed using a thematic and framework analyses method. The study population was 51 participants including health policy makers, hospital and health managers, faculty members, nurses, practitioners, community medicine specialists and other professionals of the Ministry of Health andMedical Education (MOHME).

RESULTS: According to the control knobs (health reforms levels), recruitments of effective hospital discharge planning were divided into four areas, behavior (ofpolicy makers, service providers, recipients services), organization, payment and financing and regulation (themes), in which there were 3, 7, 2 and 3 sub-themes respectively. Based on the findings of the interviews, they were categorized into the following main themes: behavior (policy makers, providers and patients), organizational change, financing and payment system and rules and regulations.

CONCLUSIONS: According to the results of the present study, it appears to be essential for health managers and policy makers to pay attention to essential requirements of effective discharge planning.

KEYWORDS: Hospital discharge planning, health system,effective discharge planning

\section{INTRODUCTION}

Discharge planning is an important aspect of health systems in many countries (1). Successful discharge planning has long been identified as the cornerstone of an effective transition of individuals from a hospital to their home (2). Discharge planning is a 
consultative process that requires several components, including assessment of a patient's current needs, appropriate anticipation of continuing care needs, and recognition of available resources to meet after-hospital care needs. Discharge planning promotes the quality of inpatient care and decreases unplanned hospital readmission. Preventing inevitable readmissions has the potential to improve both the quality of life for patients and the financial well-being of healthcare systems (3). Improvements in hospital discharge planning can significantly improve health outcomes for patients as they move to the next level of care (4).

Hospital readmission is a key focus of health reform in many countries because it is a major challenge for health systems managers (5). In recent years, avoidable readmissions rate has been signified as an indicator of the quality of hospital care (6). In Iran, despite lack of precise readmission rates, it has been estimated to be around $20-40 \%$ (7). Thus, regarding high range of unplanned readmission, hospital managers of Iranian health system must pay attention to effective discharge planning and post-hospital care to improve quality and accreditation score of their hospital (8).

Many countries in the world have been constantly trying to improve discharge planning to reduce avoidable hospital readmissions by identifying the challenges. Effective discharge planning can be dependent on many requirements such as the need for making adjustments to persons' home, determining long term funding arrangements, or the identification of a suitable care setting $(8,9)$.

Studies show that resources and requirements are central to effective discharge planning. Without these elements, discharge planning is illusory. These requirements consist of adequate assessment of readiness of patients for discharge, coherent discharge planning, suitable communication and information transfer between hospitals and community-based physicians, adequate post-discharge and follow-up (8-10).

The relevant studies are in agreement that there is no structured and effective discharge planning system in Iran. The health system of Iran has faced many challenges in the implementation of discharge planning. One of themain challengesin Iran's health system regarding discharge planning lacks patient-centered process and follows appropriate approach to discharge planning. Discharge planning in the healthcare of Iran is not a process, but it is an isolated event, which starts at the last opportunity (at the moment of discharge) instead of admission. This feature of the process leads to poor quality (10).

One of the significant policies of the Ministry of Health and Medical Education (MOHME) in Iran is implementing clinical governance and accreditation in hospitals. Interestingly, paying attention to discharge planning is inherent in both strategies. For the purpose of implementation of health reforms, it appears to be essential for hospital mangers and policy makers to pay attention to essential requirements of effective discharge planning. Therefore, the current study aimed to identify the requirements of discharge planning from the perspective of professionals in health system of Iran.

\section{MATERIALS AND METHODS}

In this qualitative study, the study population was 51 participants including health policy makers, hospital and health managers, faculty members, nurses, community medicine specialists and other professionals of the MOHME. This study was conducted in 2017. The selection process was at first purposeful (expert selection), and was completed in snowball method. It means that we started the sampling process with a convenience sample of a few research participants and asked them to suggest others for researchers to contact. These, in turn, are asked to suggest more participants. The data was gathered by means of semi-structured interviews and focus group discussions. A topic guide was made including nine questions to clarify purposes of the interviews. In detail, 25 contributors participated in four FGDs, and the rest, 25 members, were interviewed; 14 face-to-face interviews as well as

DOI: http://dx.doi.org/10.4314/ejhs.v28i2,7 
12 telephone interviews. Accordingly, the sampling process was entirely controlled by the emerging categories and ceased when data was saturated. This saturation meant that new interviews did not add new information. In this qualitative study, thematic and framework analyses were used for data analysis, comprising 5 stages of familiarization including identifying a thematic framework, indexing, charting, mapping and interpretation (11).

Proper correction was done to questions in order to attain validity and confirmation of meaningful questions in the participants' opinions. Having set the time and length of the interviews with the participants, the researchers assured them of confidentiality and asked them to allowed extracting. This was done through an initial approval plus an informed consent. In order to increase the accuracy and privacy of interviews, the researchers tried to provide a quiet place for meetings. There was no relationship between the researchers and participants. Table 1 shows the characteristics of the research participants and the setting of study.

Data collection: The durations of interviews in FGDs and semi-structured interviews were around 90-120 and 30-60 minutes, respectively. After permission, all of them were recorded using two electronic devices, to prevent some possible problems. Having listened to each recorded file two times, the researchers typed the whole discussions word-for-word and then extracted the main substantive codes. In the next step, the codes were categorized in terms of similarity. Additionally, the interviewees' noted key statements and nonverbal and facial gestures were considered when transcribing recorded files. Main research questions (RQ) were meant to investigat the experts' viewpoints about implementation requirements for patient discharge planning in health system:

- $\mathrm{RQ}_{1}$ : What is requirements for patient discharge planning in Iranian health system?

- RQ2: What is facilitators for patient discharge planning in Iranian health system?

- RQ3: What is required for effectiveness in discharge planning in Iranian health system?

Data analysis: Software MAXQDA-11 along with manual analysis was used for data analysis. Then, the themes of the requirements of discharge planning for the implementation of effective discharge planning in Iran's health system were recognized. With the purpose of increasing the credibility on the basis of Lincoln and Cuba's method of evaluative criteria, some criteria were applied (16). They included prolonged engagement, combination of data collecting method like interviews, field notes, reviewing the transcriptions and agreeing on codes and classes extracted by researchers and peer-check, and typed notes to eliminate any uncertainty of the interviewees. Moreover, the method of peer-check was applied to estimate the acceptance rate of the data. The categorizations of interviews and codes were conducted by several official experts and sophisticated in qualitative research, separately that did not have any conflict of interest in terms of the subject.

Ethical considerations: After the aims of the study had been explained, verbal agreement was obtained from the participants at the beginning of each meeting. 
Table 1: Characteristics of the research participants.

\begin{tabular}{|c|c|c|c|c|}
\hline Positions & States & Organizations & Number & $\%$ \\
\hline Faculty member & $\begin{array}{c}\text { East } \\
\text { Azerbaijan, } \\
\text { Tehran, } \\
\text { Esfahan, } \\
\text { Kerman, } \\
\text { Ardabil, } \\
\text { Kerman, } \\
\text { Shiraz }\end{array}$ & $\begin{array}{c}\text { Iran University of Medical } \\
\text { Sciences, Esfahan University } \\
\text { of Medical Sciences, Tehran } \\
\text { University of Medical } \\
\text { Sciences, Tabriz University } \\
\text { of Medical Sciences, Kerman } \\
\text { University of Medical } \\
\text { Sciences, Ardabil University } \\
\text { of Medical Sciences, Shiraz } \\
\text { University of Medical } \\
\text { Sciences }\end{array}$ & 31 & 60.78 \\
\hline Treatment manager & Tehran & MOHME & 1 & 1.96 \\
\hline $\begin{array}{l}\text { Director of } \\
\text { accreditation and } \\
\text { evaluation }\end{array}$ & Tehran & MOHME & 1 & 1.96 \\
\hline Expert in nursing & Tehran & $\begin{array}{c}\text { Iran University of Medical } \\
\text { Sciences }\end{array}$ & 2 & 3.92 \\
\hline $\begin{array}{l}\text { Office director of } \\
\text { supervision in } \\
\text { treatment }\end{array}$ & Tehran & MOHME & 2 & 3.92 \\
\hline $\begin{array}{l}\text { Nursing manager of } \\
\text { medical university }\end{array}$ & Tehran & $\begin{array}{c}\text { Iran University of Medical } \\
\text { Sciences }\end{array}$ & 1 & 1.96 \\
\hline $\begin{array}{l}\text { Director of medical } \\
\text { records }\end{array}$ & Tehran & $\begin{array}{c}\text { Iran University of Medical } \\
\text { Sciences }\end{array}$ & 1 & 1.96 \\
\hline $\begin{array}{l}\text { Director of quality } \\
\text { improvement of } \\
\text { hospital }\end{array}$ & Tehran & $\begin{array}{c}\text { Iran University of Medical } \\
\text { Sciences }\end{array}$ & 3 & 5.88 \\
\hline Nursing supervisor & Tehran & $\begin{array}{c}\text { Iran University of Medical } \\
\text { Sciences }\end{array}$ & 3 & 5.88 \\
\hline $\begin{array}{l}\text { Director of infection } \\
\text { control of hospital }\end{array}$ & $\begin{array}{l}\text { Tehran, } \\
\text { East } \\
\text { Azerbaijan }\end{array}$ & $\begin{array}{c}\text { Iran University of Medical } \\
\text { Sciences, Tabriz University } \\
\text { of Medical Sciences }\end{array}$ & 2 & 3.92 \\
\hline $\begin{array}{l}\text { Nursing manager of } \\
\text { hospital }\end{array}$ & $\begin{array}{c}\text { East } \\
\text { Azerbaijan, } \\
\text { Tehran }\end{array}$ & $\begin{array}{c}\text { Iran University of Medical } \\
\text { Sciences }\end{array}$ & 4 & 7.86 \\
\hline Total & & & 51 & 100 \\
\hline \multicolumn{5}{|c|}{$\begin{array}{ll}\text { RESULTS } & \begin{array}{l}\text { participants were Ph.D holders }(\mathrm{n}=29) . \\
\text { findings showed that the mean age was }\end{array} \\
\text { The } 51 \text { interviews and the } 4 \text { FGDs }\left(25 \quad \begin{array}{l}38.51(9.01) \text { years. Also, the mean work } \\
\text { contributors per session) were managed between } \\
\text { experience of the participants was } 10.12(8.04)\end{array}\right. \\
\begin{array}{l}\text { participants who had between } 1 \text { and } 38 \text { years of } \\
\text { years. The main fields of specializations of } \\
\text { healthcare experience. The interviewees were } 12\end{array} \\
\begin{array}{l}\text { interviewees were nursing }(n=20) \text { and healthcare } \\
\text { women and } 39 \text { men. The majority of the }\end{array}\end{array}$} \\
\hline
\end{tabular}

DOI: http://dx.doi.org/10.4314/ejhs.v28i2,7 
Table 2: Profile of interviewees

\begin{tabular}{|c|c|c|c|}
\hline \multicolumn{4}{|l|}{ Demographics $(\mathrm{n}=51)$} \\
\hline Qualitative variables & & Frequency & $\%$ \\
\hline \multirow[t]{2}{*}{ Gender } & Male & 39 & 76.47 \\
\hline & Female & 12 & 23.53 \\
\hline \multirow[t]{2}{*}{ current occupation group } & Faculty members & 31 & 60.78 \\
\hline & Non-faculty members & 20 & 39.22 \\
\hline \multirow[t]{6}{*}{ Highest level of educational degree } & Bachelor & 6 & 11.76 \\
\hline & Masters & 7 & 13.72 \\
\hline & Ph.D. & 29 & 56.86 \\
\hline & Ph.D. Candidate & 4 & 7.84 \\
\hline & GPs & 2 & 3.92 \\
\hline & MD, Specialists & 3 & 5.90 \\
\hline \multirow[t]{8}{*}{ Main field and skill } & Nursing & 20 & 39.22 \\
\hline & Healthcare Management & 16 & 31.36 \\
\hline & Epidemiology & 4 & 7.86 \\
\hline & Community Medicine & 2 & 3.92 \\
\hline & Health Information Management & 3 & 5.88 \\
\hline & Health Promotion & 2 & 3.92 \\
\hline & Medical Library & 1 & 1.96 \\
\hline & Clinical Specialist & 3 & 5.88 \\
\hline Quantitative variables & Maximum & Mean & SD \\
\hline Average age (years) & 28 & 38.51 & 9.01 \\
\hline Average work experience (years) & 38 & 10.12 & 8.04 \\
\hline
\end{tabular}

Results were divided into four areas of behavior (of policymakers, service providers and RecipientsServices), organization, payment and financing and regulation (themes), in which there were 3, 7, 2 and 3 sub-themes respectively (Figure $1)$.

\section{Main theme 1}

Behavior (policy makers, providers and patients): Behavior is defined as actions to influence activities of individuals (policy makers, providers, patients) about health and healthcare. Effective hospital discharge planning to reduce patient re-admission rates is influenced by the behaviors of care providersa nd policy makers and patients.

\section{Sub-theme 1}

Behavior of policy-makers and senior managers: Interviewees in the behavior of policy makers have expressed different views as a requirement for the successful implementation of discharge planning. This sub-theme includes the following items:

Strategic planning: The need for strategic thinking and moving forward to integrated health services delivery (CIHSD) and the need to include discharge planning in the strategic plans of the health system were the most important requirements mentioned by the vast majority of the participants: "Discharge planning and continuity of care is a missing link in health system of Iran because policy makers have treatment-based attitude rather than healthoriented. Therefore, it has not been included in the strategic plan of the health system." (P:20).

Policy makers' approach: A whole system approach for policy makers and managers to develop planning, implementation and evaluation of discharge planning is essential because of coherence and ensuring effective operation of discharge planning. Accordingly, the majority of the participants in the interviews stated, "Policy 


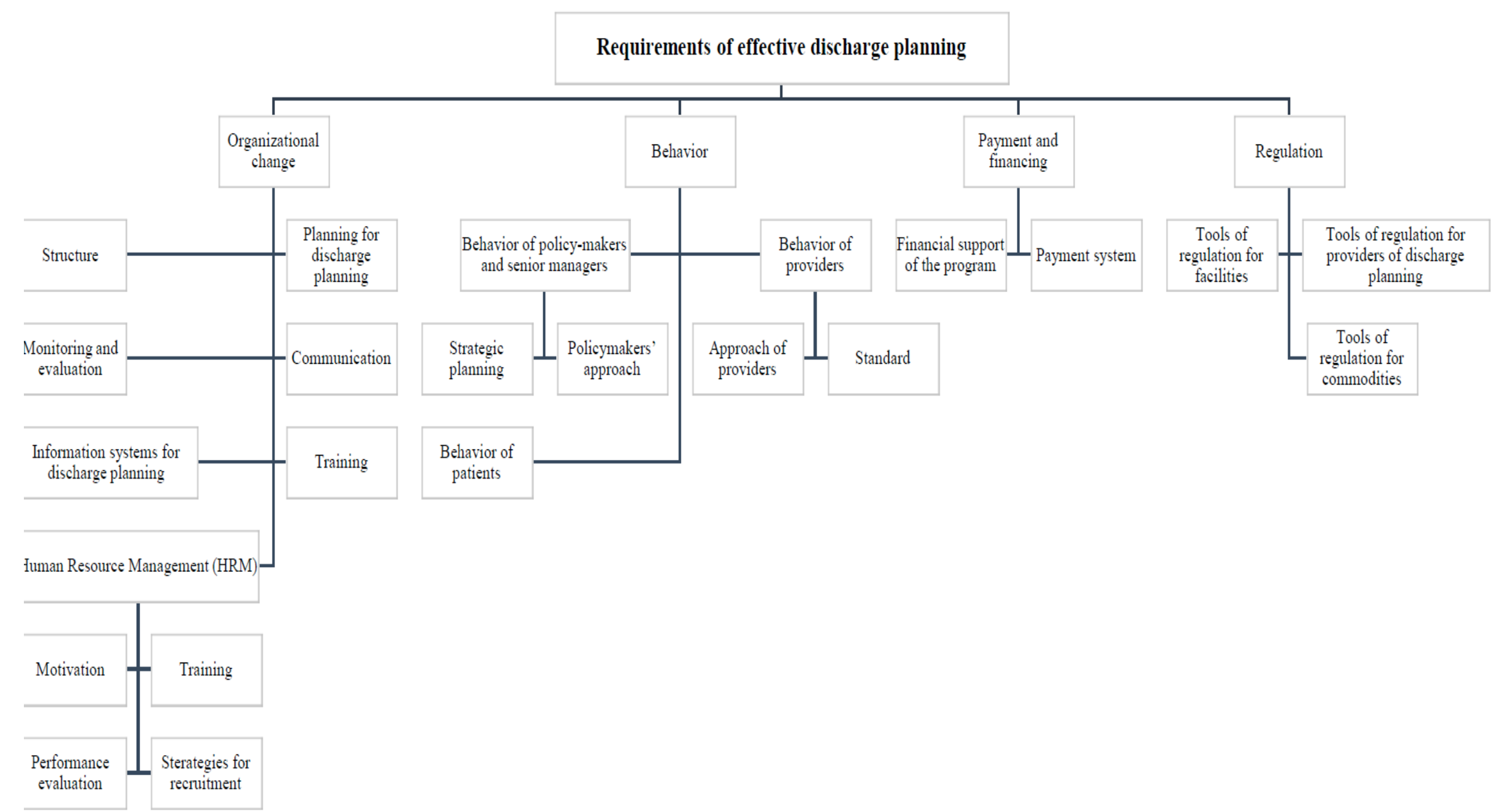

Figure 1: Coding tree

DOI: http://dx.doi.org/10.4314/ejhs.v28i2,7 
makers and managers in every three level of management should interact and coordinate with each other in the planning, performing and evaluation of discharge planning. We may have accidental good planning and policy making, but may not have a good performing and evaluation or vice versa. Lack of this approach leads to unsuccessful discharge planning." (P: 25).

Sub-theme 2

Behavior of providers: Change in service providers' behaviors plays an important role in the implementation of effective discharge planning. This sub-theme includes following items:

Standard: The vast majority of the participants were of the opinion that service providers should be provided with discharge planning based on the new guidelines, standard service packages and standards of discharge planning processes. The participants informed, "The existence of guidelines in this regard prevents the execution of programs on opinion-based performance by personnel and it is very vital in performing discharge planning." (P: 12).

Approach of providers: Discharge planning is an interdisciplinary teamwork, and providers properly play their own roles as members of their team. Physicians, nurses, social workers, psychologists, nutritionists, physiotherapists and other related staff should work together to perform a successful implementation of the discharge planning. The effective teamwork of professionals is one of the main requirements that must occur in the behavior of providers. In this vein, one of the participants reported, "Discharge planning is a process in hospital and in the community like follow-up and patient education and setting an appointment for the continuity of care in hospital or homes of patients. In addition, physicians must be participating in these activities as a member of multidisciplinary team." (P: 16).

\section{Sub-theme 3}

Behavior ofpatients: Behavior in this sense includes efforts to influence what individuals do in relation to health and healthcare. This change in the way behavior is utilized needs developing appropriate strategies. The main requirement in this area was respect to referral system by patients. One of the participants stated, "Change in the behavior of all actors, particularly service recipients is not a simple task. Generally, this type of change is accompanied with time-consuming and resistance of persons. This subject will be taken into account as the most important requirement in successful implementation of this plan." (P: 51).

\section{Main theme 2}

Organizational change: Our use of organizational change refers to how providers, i.e. ministries, hospitals, health centers and clinics are organized in terms of arrangements affecting inputs, processes and outputs of healthcare provision. As shown by the results, there are seven principal themes as follows:

\section{Sub-theme 1}

Structure: The main requirement in this area is the existence of a discharge planning system and structure for discharge planning: "We need to associate committees, managers and staff with discharge planning activities through a clear job description in the organization. In addition, organizational structure must be designed by ministry of health. Communication with community support organizations must be considered in organizational structure of discharge planning." (P: 34).

Establishment of supportive and communitybased organizations, such as homecare, family nursing agencies and long term care facilities, are essential for better implementation of discharge planning. To support the implementation of discharge planning, there should exist NGOs in society so that, if necessary, patients can utilize the services of these centers.

According to the participants, the need for defining a responsible or an appointed discharge planning leader for the implementation of discharge planning in health government is one of the most important requirements in this regard: "Identifying the leaders and a person responsible for this program in the Ministry of Health and the total levels of the referral system is one of the biggest requirements of the program." (P: 10).

\section{Sub-theme 2}

Planning for discharge planning: Discharge planning requieres developing a strategic plan for

DOI: http://dx.doi.org/10.4314/ejhs.v28i2.7 
modifying processes through modification of policies, procedures and processes to move the organization from an "as is" state to a "to be" state. Half of the study participants held that strategic planning and step-by-step procedures are requirements for successful implementation of this program. For example, "Until the strategic plan is not to become an operational program, it would not be implemented." (P: 44).

\section{Sub-theme 3}

Monitoring and evaluation: Developing a monitoring and evaluation system for discharge planning is an other fundamental requirement inorder to ensure performance of staff in accordance with principals of discharge planning: "The new system for evaluation of discharge planning needs to define a series of indicators for discharge planning." (P:43).

\section{Sub-theme 4}

Communication: Strengthening communication between service providers, i.e. inter-sectorial and intra-sectorial coordination, were of the most important themes that were raised by the majority of the study participants: "The relationship between a hospital and other organizations like the Relief Committee and welfare is welldefined." (P: 12).

\section{Sub-theme 5: Informationsystems for discharge planning}

The role of health information systems is to generate, analyse and disseminate such data. HIS must generate the data needed to monitor progress towards goals concerning discharge planning. According to the participants, the most important theme in this regard was the need for electronic health records: "In my opinion, the first thing that we need in this regard is a network of patient's information such as electronic health record and electronic health cards." $(P: 23)$.

\section{Sub-theme 6}

Training: Discharge from hospital to home requires successful transfer of information from clinicians to the patients and their family to reduce adverse events and prevent readmissions. Most respondents believed that education programs tailored to the needs of patients, such as up-to-date materials, are among the main requirements of discharge planning. The mojerity of the participants stated, "Training the staff envolved in discharge planning, such as in training courses must be designed approprately through a performance evaluation." (P:3).

\section{Sub-theme 7: Human Resource Management (HRM)}

Training: Education, changing attitudes and empowering service providers regarding hospital discharge planning are some of the basic requirements for successful implementation of this program. The majority of the participants in this study stated, "Discharge planning was considered as the end point of care in our hospitals. However, change in attitude and performance cannot be created without training." (P: 23).

Motivation: Motivation of the workforce through responding to their needs improves performance personnels should be encouraged to increase commitment and responsibility. For example, "They should improve the appreciating of good performance and definition of Tariff for discharge planning services." (P: 11).

Performance evaluation: The need for defining clear roles of workforces is a fundemental activity for performing discharge planning: "Without defining clear roles of staff for discharge planning, we would have problem with performance evaluation concerning discharge planning." (P: 39).

Sterategies for recruitment: Requiring new staff or old staff or both of them is the existening sterategy for performing discharge planning: "If you have the financial resources to employ newly trained professional staff, this method is preferred." (P: 19).

\section{Main theme 3}

Financing and payment system: Results obtained from content analysis of interviews in the third area are listed. As the results show, there are two principal sub-themes, as follows:

\section{Sub-theme 1}

Financial support of the program: Financing refers to all mechanisms contributing to raising 
the money paid for activities in the health sector. These mechanisms include taxes, insurance premiums and direct payments by patients. Discharge planning requires financial support, both within the hospital and other organizations such as nursing homes facilities, homecare organizations and primary care. The hospital will not get reimbursed for these funds for discharge planning activities, neither will any organizations involved: "We need to change reimbursement policies to support discharge planning in hospital or other organizations involved in discharge planning." (P: 40).

\section{Sub-theme 2}

Payment system: Providing payments can be vital to motivate providers to behave in acertain manner, particularly when they are contained in contractual arrangements linked to performance evaluation. The main requirment in this area was need for tariff for discharge planning services. Some of the participants stated, "Discharge planning services are orphans, without a tarriff for this services,we cannot ensure their conduct." (P: 18).

\section{Main themes 4}

\section{Rules and regulations}

Results obtained from content analysis of interviews in the fourth area are listed. The results show, there are three principal themes: tools of regulation for providers and tools of regulation for facilities and tools of regulation for commodities.

\section{Sub-theme 1}

Tools of regulation for providers of discharge planning: According to the majority of the participants of the present study, the need for mandating discharge planning in hospitals and public sector was the main requirment: "Hospitals may have to make major changes in their discharge planning process if health government have not a proposed rule about the mandating implementation of discharge planning in the hospitals."(P: 9).

\section{Sub-theme 2}

Tools of regulation for facilities: The interviewees mentioned that developing standards for accreditation of discharge planning is required: "The accreditation standards and establishment license are intended by the department of health to assure providing safe, adequate and efficient services by hospital, home care agencies, and other facilities in terms of discharge planning." $(P:$ 21). The need for controls on marketing and price for facility to provide dischage planning was the other requirment emphasized by the interviewees.

\section{Sub-theme 3}

Tools of regulation for commodities: Complaint or grieviance procedures for discharge planning services was the other case reported by the participants: "To evaluate this program, we must pay attention to complaints of patients. We should design mechanisms or procedures for complaints of patients. Hospitals must have a system for receiving and analyzing Grierance and $a$ feedbacksystem for the patients." (P: 21).

\section{DISCUSSION}

This study aimed to identify the necessary infrastructure for the implementation of discharge planning. Control levers health system regarding discharge planning represents a fundamental aspect of the structure and function of the health system which as a part of the reforms can be changed. Another important requirement derived from this study was that discharge planning should be included in the strategic plans of the health system of Iran and the other development programs of the country. Effective discharge planning has also been a priority area in Australia since 1998, USA, the United Kingdom (UK) as well as other countries $(12,13)$.

Policy makers must develope strategic planning for discharge planning based on the findings of the present study. The need for having a whole system approach and coherence in policy making, planning, implementation and evaluation for discharge planning services as well as ensuring the quality of care and maximizing organizational effectiveness are essential. Similar studies have confirmed this point $(13,14)$.

Regarding policy makers' behavior, the need for formulation of evidence-based policy for discharge planning through employing 
mechanismes for better interaction with researchers is the most important infrastructure (15). The main requirement in the field of providers' behavior was the need for performing defined tasks in accordance with practical guidelines and standard processes and service packages of discharge planning (16). Observing the cultural considerations of patients by providers was another point that is also mentioned in other studies (17). The main requirement for discharge planning in the field of consumers' behavior was cooperation and coordination with discharge planner in developing and doing their discharge plan (18).

The other main requirment in this regard was the need for organizing an interdisciplinary team to implement the discharge planning. Other studies showed that good interdisciplinary teamwork and effective leadership are critical to the success of effective discharge planning (19). Additionly, high commitment, accountability and responsibility by providers are required when performing discharge planning duties. Similar studies also have emphasized the importance of commitment and accountability in effective implementation of discharge planning (20).

In the area of organizing discharge planning, the main factor is the presence of a discharge planning system so as to design the organizational structure for discharge planning (14). Another main discharge requirement was the need for social support systems such as homecare based on hospital or community to support discharge planning. This point has been addressed in other studies and it is mentioned $(2,10)$. The need for defining an appointed person for discharge planning in the Ministery of Health and in every level of the health system in the current study and other studies are emphasized $(16,21)$.

In the area of organizing discharge planning, the other main requirment was the need for developing a monitoring and evaluation system for discharge planning and desinging indicators for it. Additionally, feedback evaluation should be presented to the staff to attain a successful implementation $(22,23)$. Other findings in the this field showed that we need a proper hospital information system and electronic health records. Another study developed the idea that integrated HIS and electronic health records will play a key role in improving the quality of patient data (24, 25).

The other main requirment was need for improving educational materials for patients to ensure better self-care after discharge. Results of similar studies also indicate that self-care responsibilities also increase in number and importance, presenting new tasks for patients and their families as they return home (26). The other large necessary need in this regard was improving staff sknowledge about discharge planning with approprate in-service training courses and including discharge planning in educational curriculum $(9,27,28)$.

According to the findings of this study, in the field of financing for this plan,the public sector would face a financial crisis and be unable to provide these services without the help of private sector and NGOs. Relevant studies also have emphasized this point.

The need for a legal framework for private service providers and NGOs is the main requirement in discharge planning. Lee and Dor stress that in the United States, many states enforce Certificate of Need (CON) regulation, where by hospitals are required to obtain approval from a designated state agency before installing additional capacity or prior to offering certain high cost services $(29,30)$.

Also, regulation of quality of care for discharge planning facilities (accreditation) by MOHME must be developed (14). Further, law of professional malpractice and regulation for lack of suitable discharge plan about discharge planning services is an essential infrastructure $(31,32)$.

The results of other studies also confirmed the findings of our study in the area of regulation tool for commodity $(21,33)$. The need for development of complaint procedures and the need for a system for receiving grieviances in hospital are extremely important for management of patients' needs and improvement of staff performance (34). Also, the need for medical

DOI: http://dx.doi.org/10.4314/ejhs.v28i2,7 
equipment for discharge planning and after hospital carerequires further studies $(35,36)$.

In conclusion, it is evident from the current study that the implementation of discharge planning system in Iran needs a variety of infrastructhers. Establishment of infrastructhers requires serious attention by managers and policy makers in the health system. Furthermore, strategies to create and promote a discharge planning needs to be adopted along with the aid of various policies, programs and supportive legislation. All of the above can work effectively in the health promotion of society, improvement of clinical outcomes for patients and reduction in the costs of health system.

\section{REFERENCES}

1. Parkes J, Shepperd S. Discharge planning from hospital to home. Cochrane Database Syst Rev. 2000; 4(2):245-53.

2. Pellett C. Discharge planning: best practice in transitions of care. British journal of community nursing. 2016; 2;21(11):542-8.

3. Alper E, A O'Malley T, Greenwald J. Hospital discharge and readmission. 2015 [updated Jun 05]; Available from: http://www.uptodate.com/contents/hospitaldischarge-and-readmission.

4. Adopting a Common Approach to Transitional Care Planning:Helping Health Links Improve Transitions and Coordination of Care [database on the Internet]. 2012. Available

from: http://www.hqontario.ca/Portals/0/Document s/bp/bp-traditional-care-planning-1404en.pdf.

5. Janati A, Hasanpoor E, Aslani F, HaghGoshayie E, Hassanzadeh E. Evaluating visit quality in plan of health sector evolution in Iran: A local survey from Tabriz. International Journal of Epidemiologic Research. 2017; 1;4(1):69-77.

6. Hassan M. Readmission of patients for hospital. International Journal for quality in health care, 2001;13(3):177-9.

7. Malek Afzali H. Methodology of applicable researches in medical sciences. Tehran
University of medical sciences. Tehran, Iran, 2005.

8. Tazhibi M, Ghaderi NM, Tirani M Causes of Readmission of Patients to Alzahra Hospital. Journal of research in Health Care. 2011;7(1):101-7.

9. Ghafari S, Mohamadi E. The Reasons of Lack of Discharge Planning Performance by Nurses. Journal of neurses. 2007;19(48):55.

10. Gholizadeh M, Delgoshaei B, Gorji HA, Torani S, Janati A. Challenges in patient discharge planning in the health system of Iran: A qualitative study. Global journal of health science. 2016;8(6):168.

11. Ibrahimipour H, Maleki MR, Gohari MR, Karimi, Dehnavieh R. aqualitative study of the difficulties in researchingsustainableuniversal health insurance coverage in Iran. Health Policy Plan. 2011;26(6):485-95.

12. Petersson $\mathrm{P}$, Springett $\mathrm{J}$, Blomqvist $\mathrm{K}$. Telling stories from everyday practice, an opportunity to see a bigger picture: a participatory action research project about developing discharge planning. Health \& social care in the community. 2009;17(6):548-56.

13. Reynolds HW, Sutherland EG. A systematic approach to the planning, implementation, monitoring, and evaluation of integrated health services. BMC health services research. 2013;13(1):168.

14. Wong EL, Yam $\mathrm{CH}$, Cheung AW, Leung MC, Chan FW, Wong FY, et al. Barriers to effective discharge planning: a qualitative study investigating the perspectives of frontline healthcare professionals. $B M C$ health services research. 2011;11(1):242.

15. Haines A, Kuruvilla S, Borchert M. Bridging the implementation gap between knowledge and action for health. Bulletin of the World Health Organization. 2004;82(10):724-31.

16. Janati A, Hasanpoor E, Hajebrahimi S, Sadeghi-Bazargani H. Health care managers' perspectives on the sources of evidence in evidence-based hospital management: A qualitative study in Iran. Ethiopian Journal of Health Sciences. 2017;27(6):659-68. 
17. Anthony MK, Hudson-Barr DC. Successful patient discharge: A comprehensive model of facilitators and barriers. Journal of Nursing Administration. 1998;28(3):48-55.

18. Coleman EA, Smith JD, Frank JC, Min SJ, Parry C, Kramer AM. Preparing patients and caregivers to participate in care delivered across settings: the Care Transitions Intervention. Journal of the American Geriatrics Society. 2004;52(11):1817-25.

19. Pethybridge J. How team working influences discharge planning from hospital: a study of four multi-disciplinary teams in an acute hospital in England. Journal of interprofessional care. 2004;18(1):29-41.

20. Beck L, Miller BK, Adams D. Use of the code of ethics for accountability in discharge planning. InNursing forum. Blackwell Publishing Ltd. 1993; 3(28): 5-12.

21. Mamon J, Steinwachs DM, Fahey M, Bone LR, Oktay J, Klein L. Impact of hospital discharge planning on meeting patient needs after returning home. Health services research. 1992;27(2):155.

22. Evans RL, Hendricks RD. Evaluating hospital discharge planning: a randomized clinical trial. Medical care. 1993;31(4):358.

23. Solomon R, Damba C, Bryant S. Measuring quality at a system level: an impossible task? The Toronto Central LHIN Experience. Healthcare quarterly (Toronto, Ont). 2012;16(4):36-42.

24. Burton LC, Anderson GF, Kues IW. Using electronic health records to help coordinate care. Milbank Quarterly. 2004;82(3):457-81.

25. Coleman EA, Berenson RA. Lost in transition: challenges and opportunities for improving the quality of transitional care. Annals of internal medicine. 2004;141(7):533-6.

26. Kripalani S, Jackson AT, Schnipper JL, Coleman EA. Promoting effective transitions of care at hospital discharge: a review of key issues for hospitalists. Journal of Hospital Medicine. 2007;2(5):314-23.

27. Watts R, Pierson J, Gardner H. Critical care nurses' beliefs about the discharge planning process: A questionnaire survey. International Journal of Nursing Studies. 2006;43(3):269-79.

28. Bray-Hall S, Schmidt K, Aagaard E. Toward Safe Hospital Discharge: A Transitions in Care Curriculum for Medical Students. $J$ Gen Intern Med. 2010;25(8): 878-81.

29. Li S, Dor A. How do hospitals respond to market entry? Evidence from a deregulated market for cardiac revascularization. Health economics. 2015;24(8):990-1008.

30. Naylor M, Keating SA. Transitional care: moving patients from one care setting to another. The American journal of nursing. 2008;108(9):58.

31. Lahey W, Currie R. Regulatory and medicolegal barriers to interprofessional practice. Journal of Interprofessional Care. 2005;19(sup 1):197-223.

32. Jankowski J, Seastrum T, Swidler RN, Shelton W, editors. For lack of a better plan: A framework for ethical, legal, and clinical challenges in complex inpatient discharge planning. HEC forum; 2009; 21(4):331-346.

33. Coleman EA. Falling through the cracks: challenges and opportunities for improving transitional care for persons with continuous complex care needs. Journal of the American Geriatrics Society. 2003;51(4):549-55.

34. Allen LW, Creer E, Leggitt M. Developing a patient complaint tracking system to improve performance. The Joint Commission Journal on Quality and Patient Safety. 2000;26(4):217-26.

35. Dudas V, Bookwalter T, Kerr KM, Pantilat SZ. The impact of follow-up telephone calls to patients after hospitalization. The American journal of medicine. 2001;111(9):26-30.

36. Yam $\mathrm{CH}$, Wong EL, Cheung AW, Chan FW, Wong FY, Yeoh E-k. Framework and components for effective discharge planning system: a delphi methodology. BMC health services research. 2012;12(1):396. 